\title{
Electo-optic and spectroscopic study of pyridine liquid crystal molecule and its deivatives
}

\author{
Pranav Upadhayay ${ }^{1}$, Jitendra Kumar ${ }^{2}$, Devesh Kumar ${ }^{3 *}$ \\ Research Scholar, Department of Applied Physics, School for Physical Sciences, \\ BabasahebBhimraoAmbedkar University, Lucknow, India ${ }^{1,2}$ \\ Associate Professor, Department of Applied Physics, School for Physical Sciences, \\ BabasahebBhimraoAmbedkar University, Lucknow, India ${ }^{3}$
}

\begin{abstract}
Four pyridine derivative and one simmilar but non-pyridine liquid crystal molecules with two aromatic and one cyclohexane ringed have been examined applying quantum mechanical tools like computational Density Functional Theory, to understand theirelectro-optical and spectroscopic details. The present article reports some liquid crystal moleculesnamely (1). 5-(4-butylcyclohexyl)-2-(4-methoxyphenyl)pyridine, (2). 5-(4-butylcyclohexyl)-2-(3fluoro-4-methoxyphenyl)pyridine, (3). 5-(4-butylcyclohexyl)-2-(2-fluoro-4-methoxyphenyl)pyridine, (4). 5-(4pentylcyclohexyl)-2-(4-propylphenyl)pyridine and (5). 1-(4-pentylcyclohexyl)-4-(4-propylphenyl)benzene.having structure of pyridine and its derivative.it was found that differences at micro level will also be responsible for the changes in optical properties like birefringence, dielectric anisotropy, etc. as well as materialistic features like viscosity, elastic constant, etc.
\end{abstract}

Keywords: pyridine, liqid crystal, density functional theory, electro-optic, spectroscopic.

\section{INTRODUCTION}

Liquid crystal is an intermediate phase of matter (between isotropic liquid and crystal). these molecules were originally discovered in chemical and biological system. Since long time, liquid Crystals (LCs) have been the subject of theoretical and experimental study. By their role in chemical, biological and elctro-optical system, they have many industrial applications. Liquid crystals arepowerful solvent in holding donor-spacer-acceptor systems as well as in maintain the fluid and order property over a wide range of temperatures too. Numerous electronic and optical properties of LC varies with change of substituent. These properties of molecules can be altered by the presence of different substituents. LC molecule have a dipole moment directly perpendicular to the molecular axis.[1-5]

The pyridine derivatives have been examined quantum mechanically to understand the possible reason for varying mesogenic character. The understanding the LC property

of these pyridine is of fundamental importance in chemical physics.Raman scattering depends on the polarizability. The Homo-Lumo energy gap is effective for stability of the molecule. Also the electrical transport property determine by the Homo-Lumo gap. [6-7]A surficial study on the vibrational analysis and elctro-optical properties was necessary and has been performed successfully in our study.In this article, we have done geometry optimization, vibrational analysis and total energy calculation of some pyridine derivatives namely (1).5-(4-butylcyclohexyl)-2(4-methoxyphenyl)pyridine, (2).5-(4-butylcyclohexyl)-2(3-fluoro-4-methoxypheny 1)pyridine, (3). 5-(4butylcyclohexyl)-2-(2-fluoro-4-methoxyphenyl)pyridine, (4).5-(4-pentylcyclohexyl)-2-(4-propylphenyl)pyridine and $\quad$ 1-(4-pentylcyclohexyl)-4-(4propylphenyl)benzene.

\section{METHODOLOGY}

The structures were designed using GaussView 5.0.

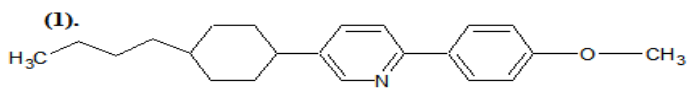

5-(4-butylcyclohexyl)-2-(4-methoxyphenyl)pyridine
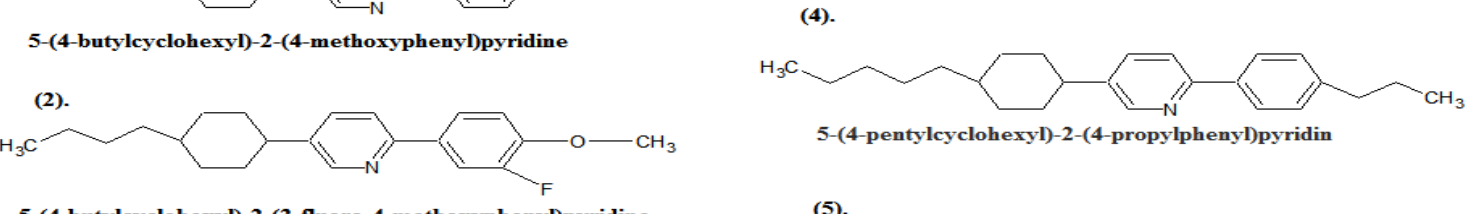

5-(4-butylcyclohexyl)-2-(3-fluoro-4-methoxyphenyl)pyridine

(3).
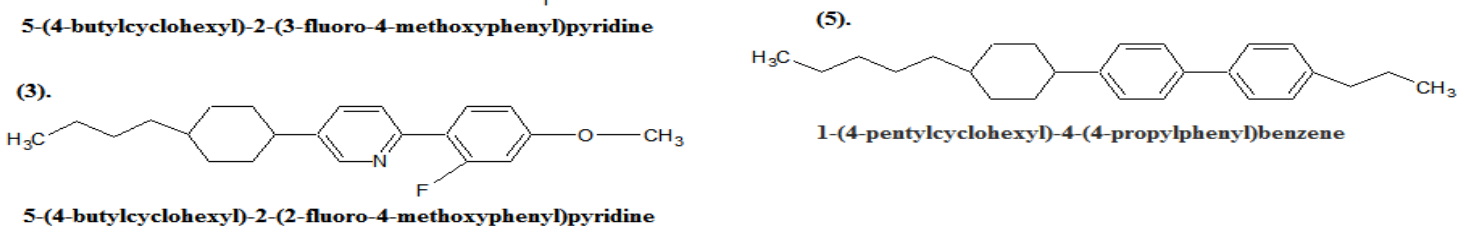

Fig.1. Chemical structures of some pyridine liquid crystal molecules 

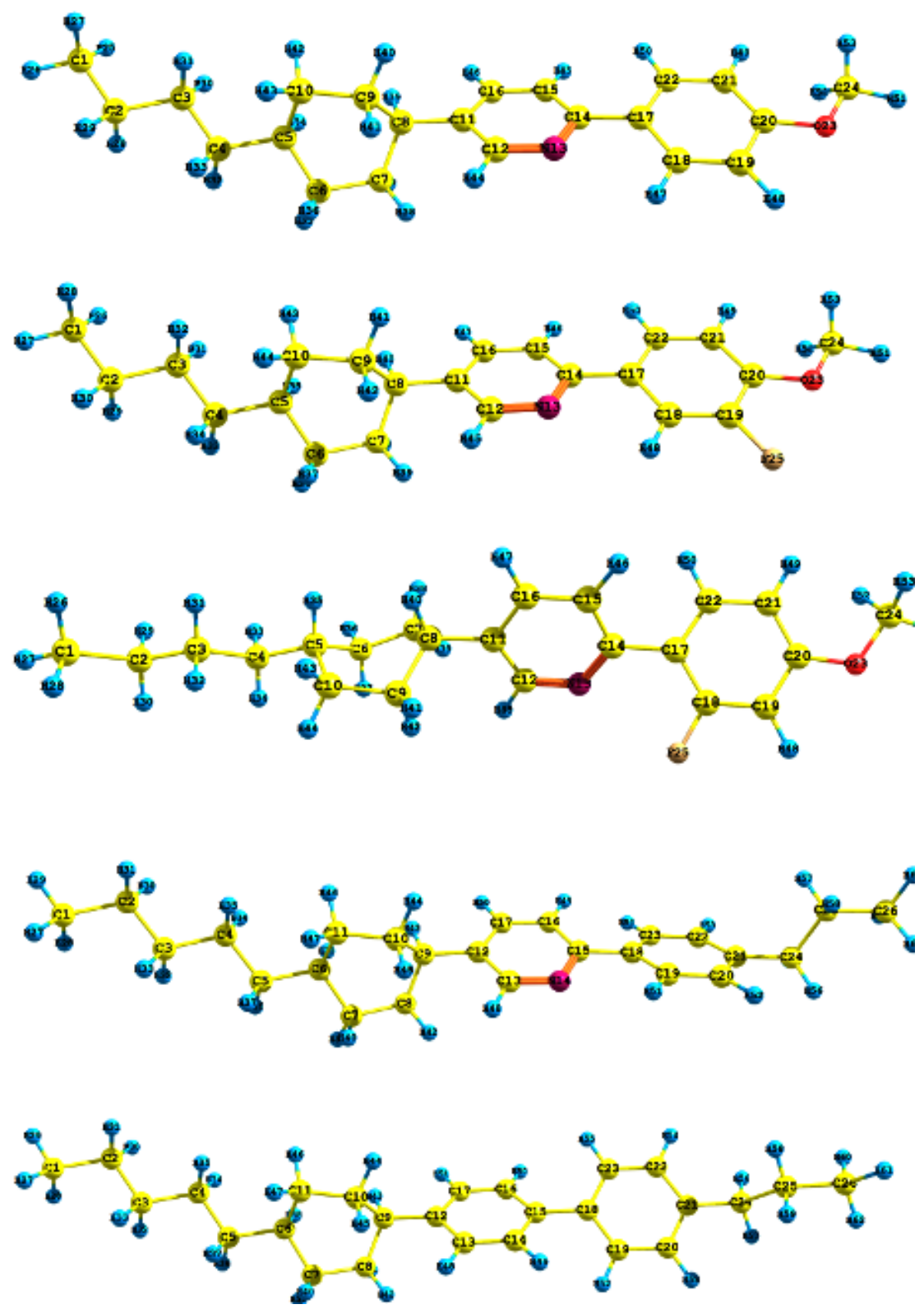

Fig.2. Optimized geometry of some pyridine liquid crystal molecules

Optimization of molecular geometry and frequencies as compound (1) at - 985.817 a.u. HOMO-LUMO gap of well as total energy calculations were carried out without compound (5) is 0.18932 a.u. which is highest among any constraint through computational density-functional these while at 0.17109 , it is lowest for compound (2).

theory (DFT) method B3LYP [8,9] which is a hybrid Dipole moment shows large variation from 0.1768 a.u. to functional for Gaussian type orbitals (GTOs) and 6- 3.8606 a.u. for compound (5) and (2) respectively. $31 \mathrm{G}^{* *}[10]$ basis set using Gaussian 09[11]. So far DFT Polarizability of compound (5) is highest at 292.51533 a.u. has been very successful in the past for (polarizability for compound (4), being at 291.574 a.u., is predicting,characterizing and explaining the properties of very near to that of compound (1)). It is lowest for various class of molecules, clusters, etc.[12,13]

\section{III.RESULTS}

Electro-optical properties likepolarizability, total energy, HOMO-LUMO gap and dipole moment of compounds (1) to (5) have been tabulated in table 1. Spectroscopic results namely IR and Raman, soobtained, has been shown in figure 2 and 3 . It is summarized in table 3.

\section{$A$. Electro-optical properties}

Total energy is lowest for compound (2) and (3) which is around -1085.043 atomic units (a.u.) while it is highest for compound (3) at 256.72933a.u.

\section{B. Spectroscopic results}

Infra-Red peak frequency is lowest for compound (1) at $1300 \mathrm{~cm}^{-1}$ and highest for compound (4) and (5) reaching to $1500 \mathrm{~cm}^{-1}$. Molar extinction coefficient $(\varepsilon)$ is greatest for compound (2) at 1100and smallest for compound 4 at 600. Frequency peak of Raman intensity spectra is maximum for compound (2) at $1700 \mathrm{~cm}^{-1}$ and rest all has $1650 \mathrm{~cm}^{-1}$. Compound (3) is producing intensity 50 which least amongst all. Intensity moves upto 120 for compound (1) and (2). 
International Advanced Research Journal in Science, Engineering and Technology Vol. 2, Issue 10, October 2015

TABLE 1. Elctro-optical propertiesofpyridine liquid crystal molecules

\begin{tabular}{|c|c|c|c|c|}
\hline COMPOUND & $\begin{array}{c}\text { POLARIZABILITY } \\
\text { (a.u.) }\end{array}$ & $\begin{array}{c}\text { TOTAL ENERGY } \\
\text { (a.u.) }\end{array}$ & $\begin{array}{c}\text { HOMO-LUMO } \\
\text { GAP (a.u.) }\end{array}$ & $\begin{array}{c}\text { DIPOLE } \\
\text { MOMENT (a.u.) }\end{array}$ \\
\hline 1 & 261.31233 & -985.81772412 & 0.17297 & 2.5430 \\
\hline 2 & 262.18166 & -1085.04374730 & 0.17109 & 3.8606 \\
\hline 3 & 256.72933 & -1085.04356918 & 0.18457 & 3.4265 \\
\hline 4 & 291.574 & -1028.56133046 & 0.17937 & 1.8105 \\
\hline 5 & 292.51533 & -1012.52375221 & 0.18932 & 0.1768 \\
\hline
\end{tabular}

TABLE 2. Spectroscopic propertiesofpyridine liquid crystal molecules

\begin{tabular}{|c|l|l|l|l|}
\hline COMPOUND & \multicolumn{2}{|c|}{ INFRA RED } & RAMAN INTENSITY \\
\hline & $\begin{array}{c}\text { Frequency } \\
\text { peak }\left(\mathbf{c m}^{-1}\right)\end{array}$ & $\begin{array}{c}\text { Molar } \\
\text { extinction } \\
\text { coefficient( }(\varepsilon)\end{array}$ & $\begin{array}{l}\text { Frequency } \\
\text { peak }\left(\mathbf{c m}^{-1}\right)\end{array}$ & Intensity \\
\hline 1 & 1300 & 850 & 1650 & 120 \\
\hline 2 & 1400 & 1100 & 1700 & 120 \\
\hline 3 & 1400 & 850 & 1650 & 50 \\
\hline 4 & 1500 & 600 & 1650 & 110 \\
\hline 5 & 1500 & 750 & 1650 & 110 \\
\hline
\end{tabular}

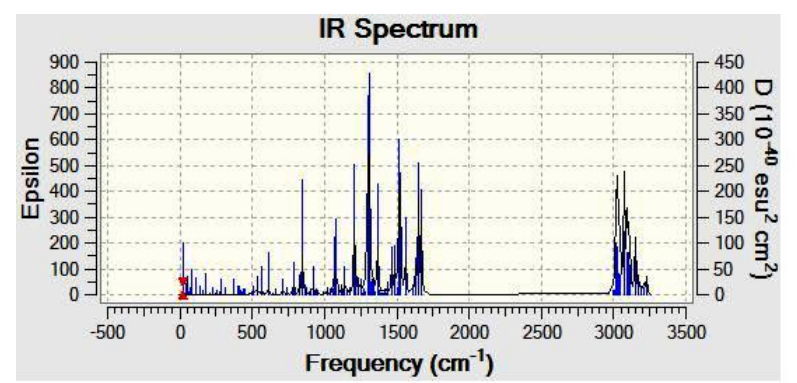

(1).

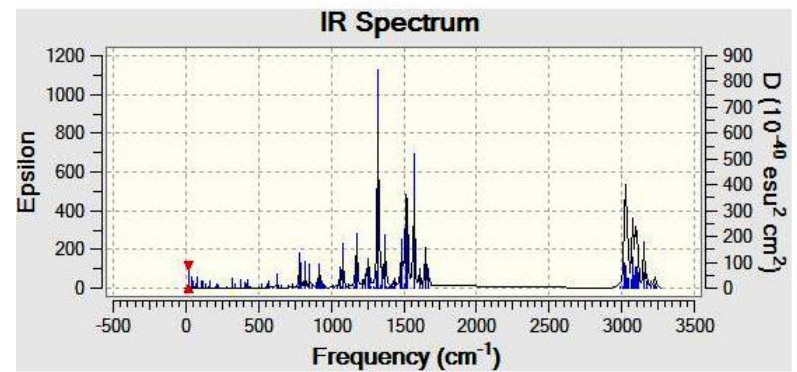

(2).

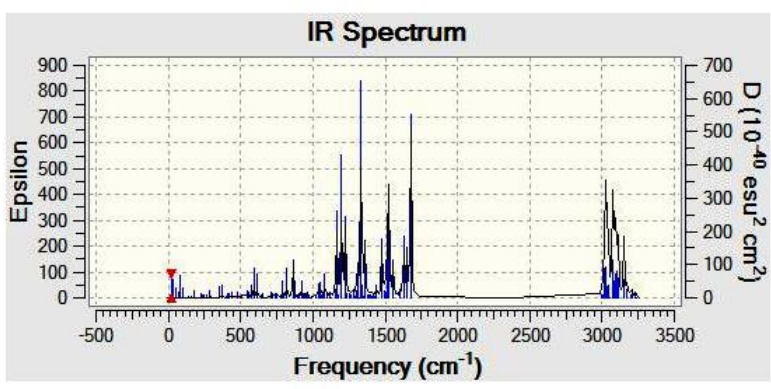

(3).

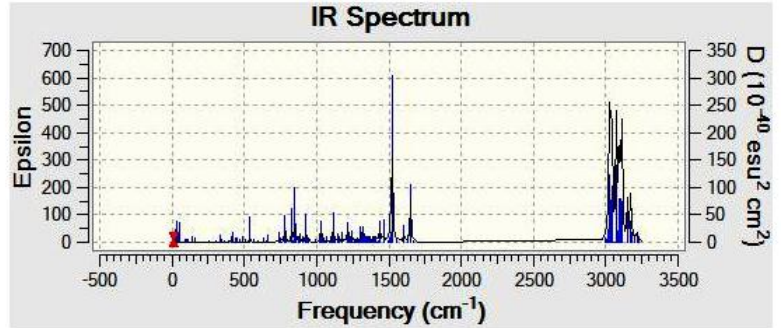

(4).

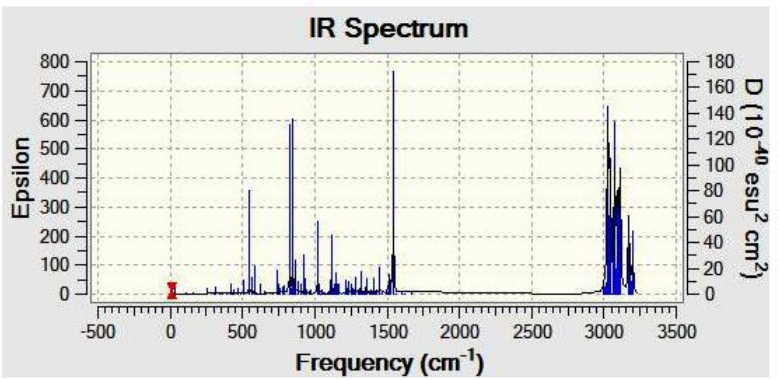

(5).

Fig.3. IR spectra of some pyridine liquid crystal molecules 
International Advanced Research Journal in Science, Engineering and Technology

Vol. 2, Issue 10, October 2015
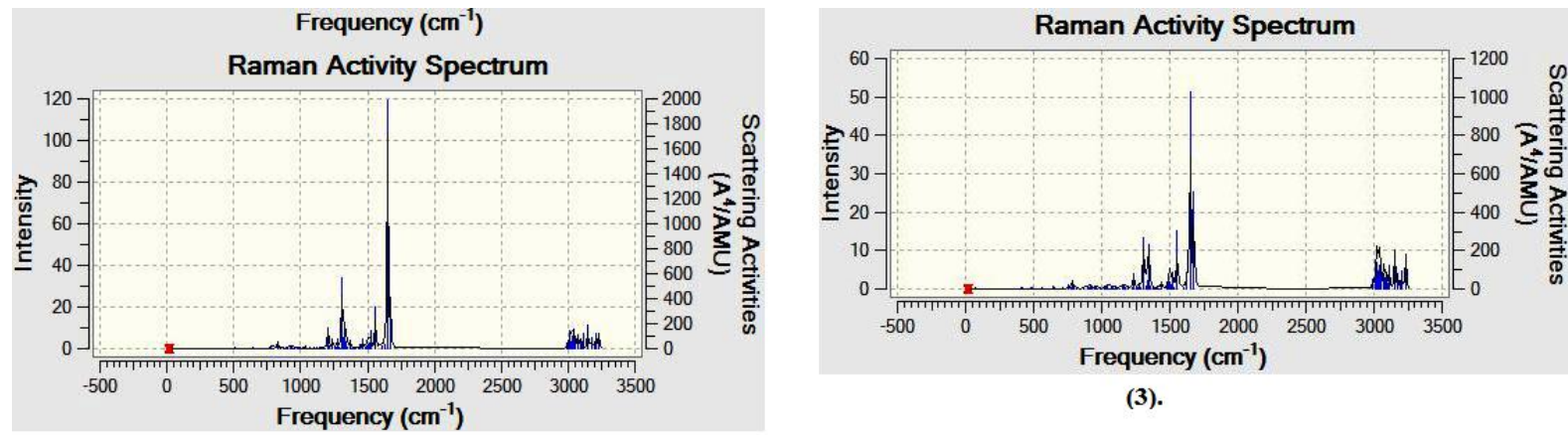

(3).

(1).
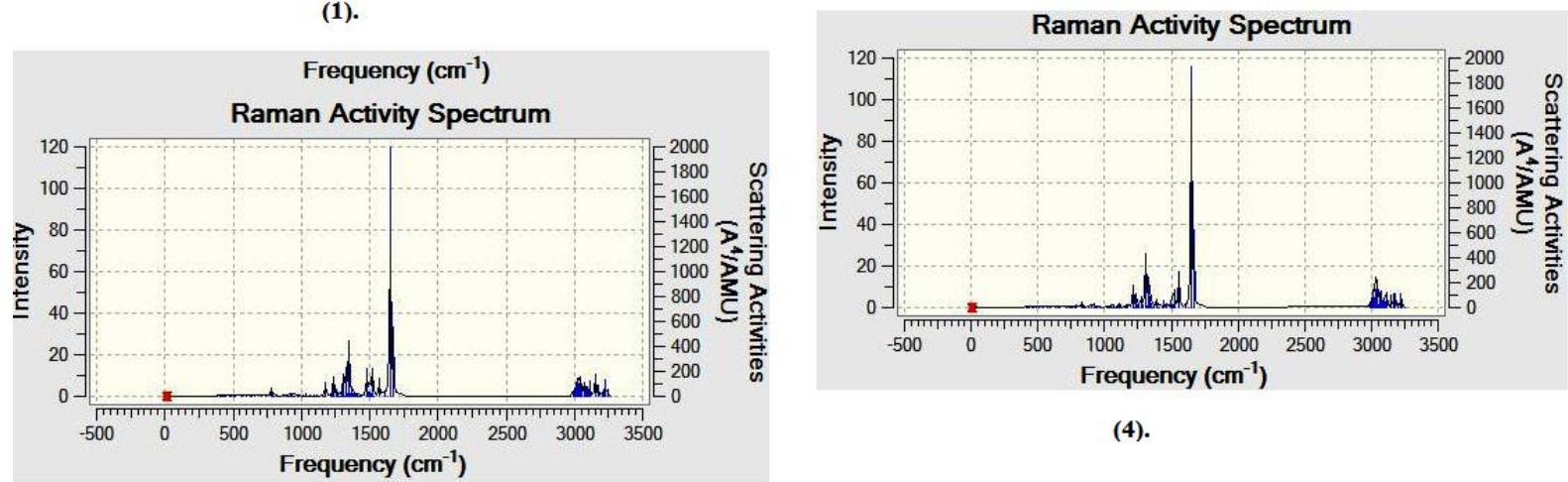

(4).

(2).

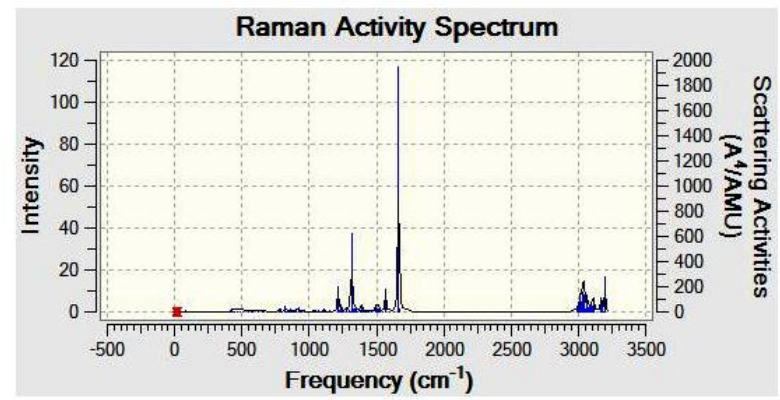

(5).

Fig.3. Raman spectra of some pyridine liquid crystal molecules

\section{DISCUSSION}

Total energy of compound (1) is highest and that of compound (2) and (3) is lowest although all these are having almost same basic structure, only difference is the presence of fluorine in (2) and (3) at different positions of benzene ring. HOMO-LUMO gap of compound (5) is greater than all others though HOMO-LUMO gapof compound (3) is very near to that of former. This may be due to absence of any atom having lone pair electrons in former and presence of nitogen in the vicinity fluorine in the latter. This above said reason is also determining factor in generating dipole moment, as we can see dipole moment of compound (5) is lowest and that of compound (2) is highest which is due to presence of oxygen as well as fluorine ( two most electronegative atoms ) on same side of the molecule. Compound (4) and (5) have most no. of atoms thus having most no. of electrons, leading to higher polarizability amongst all.

All the molecules have same basic structure that is two side by side aromatic rings along with third aromatic ring an alkyl chains at the both ends in (4) and (5) or at one end in (1), (2)and (3). That's why, we are getting simmilar IR and Raman spectra for all these molecules with some minor differences pertaining to presence or absence of atoms like nitrogen, oxygen and fluorine.

\section{CONCLUSION}

Not only mere presence but also the position of subtituent is affecting the elctro-optical as well as spectroscopic results that will lead to some major differences when present in bulk. These differences at micro level will also be responsible for the changes in optical properties like birefringence, dielectric anisotropy, etc. as well as materialistic features like viscosity, elastic constant, etc.

\section{REFERENCES}

[1] ND Mermin, in "The topological theory of defects in ordered media".inRev Mod Phys.,vol. 51. pp. 591-648. 1979

[2] H-R Trebin, in "The topology of non-uniform media in condensed matter physics" in Adv Phys., vol. 31.pp.195-254. 1982

[3] U. Heinen, T. Berthold, G. Kothe, E. Stavitski, T. Galili, H. Levanon, G. Wiederrecht, and M. R. Wasielewski, in "High Time Resolution Q-Band EPR Study of Sequential Electron Transfer in a Triad Oriented in a Liquid rystal" inj. Phys. Chem.. A, vol.106, pp.1933-1937., 2002

[4] MihirRoychoudhury, Shailendra Kumar Thakur, Pankaj Kumar Gaurav, "Estimation of mesogenic character of disubstituted pyridine derivatives on the basis of intermolecular interaction 
energy calculations Journal of molecular Liquids" in vol.161,pp. $55-62,2011$

[5] M. Roychoudhury, P. K. Gaurav, R. Manohar and A. K. Prajapati," Analysis of Mesogenic Characteristics of 6-Chloro-benzothiazol-2yl-(4-exadecyloxyphenyl) Diazene-A Smectic Liquid Crystal Mol. Cryst. Liq. Cryst.,in Vol. 537, pp. 3-21, 2011

[6] Vladimir F. Petrov study of some liquid crystalline 2,5disubstituted pyridine derivatives Mol. Cryst. Liq. Cryst.,in vol. 383, pp. 63-79,2002

[7] P. L. Praveen And D. P. Ojha, In "Effect Of Molecular Interactions And Homologue Number On Uv Absorption Spectra Of Liquid Crystalline Alkyl Cyanobiphenyl Dimers: Dft Calculations" in ., Mol. Cryst. Liq. Cryst., Vol. 606: Pp. 75-89, 2015

[8] A. DBecke.,Density-functional thermochemistry. III. The role of exact exchangein,J. Chem., Phys,vol. 98, pp.5648-5652, 1993

[9] C.Lee., W. Yang, R.G. Parr,Development of the Colle-Salvetti correlation-energy formula into a functional of the electron density.Phys. Rev. B, vol.37, pp.785, 1988.

[10] P. J. Hay, W. Wadt..",A $b$ initio effective core potentials for molecular calculations. Potentials for the transition metal atoms Sc to Hg."J. Chem. Phys., vol.82,pp. 270-284, 1985.

[11] Gaussian-09, Revision B.01, M. J. Frisch, G. W. Trucks, H. B. Schlegel, G. E. Scuseria, M. A. Robb, J. R. Cheeseman, G. Scalmani, V. Barone, B. Mennucci, G. A. Petersson, H. Nakatsuji, M. Caricato, X. Li, H. P. Hratchian, A. F. Izmaylov, J. Bloino, G. Zheng, J. L. Sonnenberg, M. Hada, M. Ehara, K. Toyota, R. Fukuda, J. Hasegawa, M. Ishida, T. Nakajima, Y. Honda, O. Kitao, H. Nakai, T. Vreven, J. A. Montgomery, Jr., J. E. Peralta, F. Ogliaro, M. Bearpark, J. J. Heyd, E. Brothers, K. N. Kudin, V. N. Staroverov, T. Keith, R. Kobayashi, J. Normand, K. Raghavachari, A. Rendell, J. C. Burant, S. S. Iyengar, J. Tomasi, M. Cossi, N. Rega, J. M. Millam, M. Klene, J. E. Knox, J. B. Cross, V. Bakken, C. Adamo, J. Jaramillo, R. Gomperts, R. E. Stratmann, O. Yazyev, A. J. Austin, R. Cammi, C. Pomelli, J. W. Ochterski, R. L. Martin, K. Morokuma, V. G. Zakrzewski, G. A. Voth, P. Salvador, J. J. Dannenberg, S. Dapprich, A. D. Daniels, O. Farkas, J. B. Foresman, J. V. Ortiz, J. Cioslowski, and D. J. Fox, GaussianInc., Wallingford CT, (2010)

[12] A.K. Vardhaman, P. Barman., S. Kumar., C.V.Sastri, D. Kumar ,S.P. de Visser ."Comparison of the Reactivity of NonhemeIron(IV)-Oxo versus Iron(IV)-Imido Complexes: Which is the Better Oxidant?" inAngew. Chem. Int.vol.52, pp.1228812292,2013

[13] D. Umadevi, S.Panigrahi, G.N. Sastry “.Noncovalent Interaction of Carbon Nanostructures"'inAcc. Chem. Res.vol. 47,pp. 2574-2581, 2014 